\title{
PKQuest: volatile solutes - application to enflurane, nitrous oxide, halothane, methoxyflurane and toluene pharmacokinetics
} David G Levitt

Address: Department of Physiology, 6-125 Jackson Hall, 321 Church St. S. E., Minneapolis, MN 55455

E-mail: levitt@dcmir.med.umn.edu

Published: 15 August 2002

BMC Anesthesiology 2002, 2:5
Received: 4 April 2002

Accepted: 15 August 2002

This article is available from: http://www.biomedcentral.com/I47/-2253/2/5

(C) 2002 Levitt; licensee BioMed Central Ltd. This article is published in Open Access: verbatim copying and redistribution of this article are permitted in all media for any non-commercial purpose, provided this notice is preserved along with the article's original URL.

\begin{abstract}
Background: The application of physiologically based pharmacokinetic models (PBPK) to human studies has been limited by the lack of the detailed organ information that is required for this analysis. PKQuest is a new generic PBPK that is designed to avoid this problem by using a set of "standard human" default parameters that are applicable to most solutes.

Results: PKQuest is used to model the human pharmacokinetics of the volatile solutes. A "standard human" value for the lipid content of the blood and each organ (klip) was chosen. This set of klip and the oil/water partition coefficient then specifies the organ/blood partition for each organ. Using this approach, the pharmacokinetics of inert volatile solute is completely specified by just 2 parameters: the water/air and oil/water partition coefficients. The model predictions of PKQuest were in good agreement with the experimental data for the inert solutes enflurane and nitrous oxide and the metabolized solutes halothane and toluene.
\end{abstract}

Methods: The experimental data that was modeled was taken from previous publications.

Conclusions: This approach greatly increases the predictive power of the PBPK. For inert volatile solutes the pharmacokinetics are determined just from the water/air and oil/water partition coefficient. Methoxyflurane cannot be modeled by this PBPK because the arterial and end tidal partial pressures are not equal (as assumed in the PBPK). This inequality results from the "washinwashout" artifact in the large airways that is established for solutes with large water/air partition coefficients.

PKQuest and the worked examples are available on the web [www.pkquest.com].

\section{Background}

PKQuest is a new generic "physiologically based pharmacokinetic model" (PBPK) [1]. A PBPK provides an approach to modeling drug distribution and metabolism that is based on the use of a physiologically realistic model of the animal. This new PBPK has been designed to provide a rigorous mathematical treatment that takes into consideration all the different biochemical and physio- logical properties that a drug may have, and yet be very simple to use. Other papers in this series have described the application of PKQuest to propranolol, $\mathrm{D}_{2} \mathrm{O}$, ethanol, inulin and protein bound antibiotics [1-3]. This paper will describe the application of PKQuest to volatile solutes, with particular emphasis on anesthetics. 
The use of a PBPK to model pharmacokinetics requires detailed information about the blood-tissue partition coefficient for each organ. This is the feature that has limited the applications of PBPK to human studies since it is normally assumed that these tissue partition coefficients must be determined for each specific solute that is studied. The major design philosophy behind PKQuest is to increase the predictive power of the PBPK so that it can applied to a large variety of solutes without the need for this specific information. This is accomplished by preprogramming a "standard human" data set that contains most of the information that is required to model the different solutes. The new approach for the volatile solutes that is developed in this paper is to assume that the tissue partition of these solutes is determined entirely by a) the oil/water partition coefficient and b) the fraction of lipid in the blood and each organ i (klip [i]). A set of "standard human" values for klip [i] is assigned for each organ. Using this assumption, the pharmacokinetics of any inert volatile solute is completely determined (as a first approximation) by just 2 parameters: the water/air (Kwair) and oil/ water (Kfwat) partition coefficients. This allows PKQuest to be used to predict the pharmacokinetics of any inert volatile solute for which experimental values for these simple physical chemical parameters are available. If the solute is metabolized (as is the case for halothane and toluene) then additional adjustable parameters (e.g., metabolic liver Km and Vmax) must be added.

As a test of this approach to modeling volatile solutes, PKQuest was applied to the simultaneous uptake and washout measurements of Munson et al. [4] and Carpenter et al. [5] for $\mathrm{N}_{2} \mathrm{O}$, enflurane, halothane, and methoxyflurane. Application of PKQuest to these simultaneous anesthetic measurements provides a stringent test of the PKQuest assumptions because only the specific partition coefficients (Kbair, etc) vary for the different gases while all the other parameters (e.g. percent body fat, klip, fat blood flow, ventilation, etc.) must be identical. In addition, using the same set of parameters to fit the roughly 20 fold difference in concentration between the Munson et al. and Carpenter et al. data provides another test. Finally, to show that the validity of this approach extended beyond the anesthetics, it was also applied to toluene, a volatile solute for which detailed human PBPKs are already available. Since the value of the oil/water partition coefficient varies from 3 for nitrous oxide to 120 for toluene, the ability of PKQuest to model these different solutes using a single set of organ fat fractions (klip) demonstrates the generality of this approach.

Anesthesiologists have used physiological models incorporating air/water partition coefficients and volumes of distribution to predict the kinetics for more than a 150 years [6]. However, there have been only a few applica- tions of detailed, organ specific PBPK to anesthetics. Mapleson and colleagues developed a detailed anesthetic PBPK [7-9] and measured the relevant PBPK parameters [10-12]. Smith and colleagues $[13,14]$ and Fukui and Smith $[15,16]$ have developed complex PBPKs in which the anesthetic interacts with and modifies the organ parameters. The primary application of these models has been to illustrate the theoretical importance of the different model components. The only detailed attempts to fit human data with a PBPK are for nitrous oxide in man [17] and halothane in infants [18]. Allott, Steward and Mapleson [19] also fit a PBPK to the experimental data for halothane in the dog. Both of these halothane studies were incomplete because they did not account for metabolism. The most complete PBPK for halothane is the rat study of Loizou et al. [20] which includes a metabolic component that is saturable and inactivates. There have been no previous attempts to use a PBPK to model multiple, simultaneously measured anesthetics such as is described in this paper.

In contrast to the PBPK model of Mapleson [7], PKQuest does not model the vascular time delays and therefore is not applicable to short time kinetics (less than a minute). However, PKQuest does incorporate a number of features that are not present in Mapleson's model, including tissue metabolism, capillary limitation (either in the lung or tissue) and ventilation-perfusion mismatch.

The PKQuest program and all the examples used here are freely available on the WEB at [www.pkquest.com]. The reader is encouraged to download these routines and try them out.

\section{Methods}

\section{PBPK program and its assumptions}

PKQuest [1] was used for all the analysis in this paper. All the figures shown in this paper are direct copies (in jpeg format) of standard PKQuest output. PKQuest makes several simplifying assumptions (see [1]). It is assumed that each organ can be modeled as a single well-stirred compartment. For the volatile solutes studied here, it is also assumed that the blood-tissue exchange is flow limited so that the partial pressure in the tissue is equal to that in the vein leaving the tissue. This is clearly an approximation and effects such a diffusion gradients, countercurrent exchange and heterogeneous organ blood flows [21-23] will produce small deviations from this assumption. It is also assumed that the influence of the anesthesia in the Carpenter et al. studies on the PBPK parameters can be neglected [14,24]. Although these solutes may consist of stereo enantiomers, it is assumed that there is no significant difference in the pharmacokinetics of the enantiomers, which is supported by experiment $[25,26]$. It is 


\section{Enflurane}

\section{Carpenter et. al.}

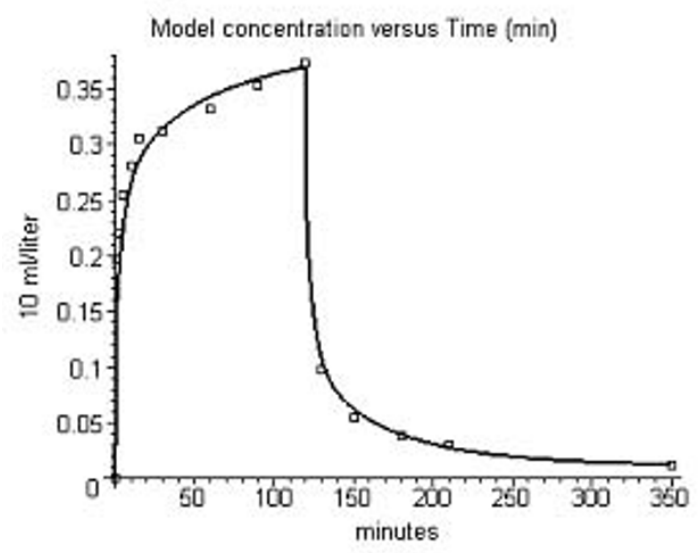

Model concentration versus Time (min)
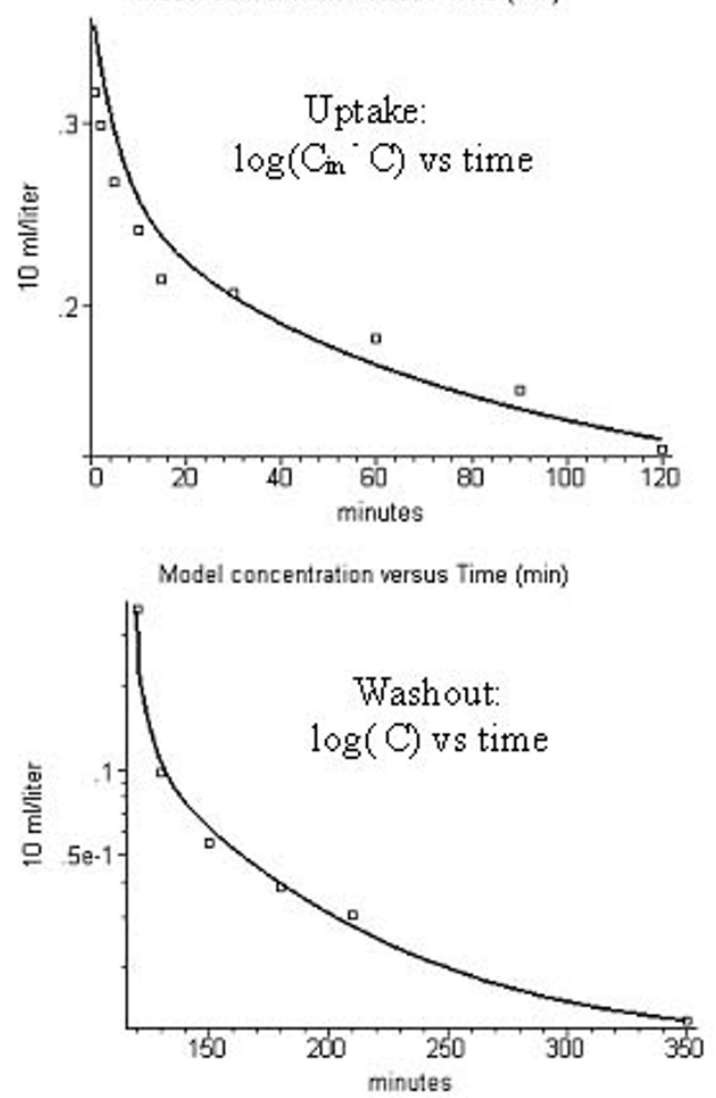

Munson et. al.
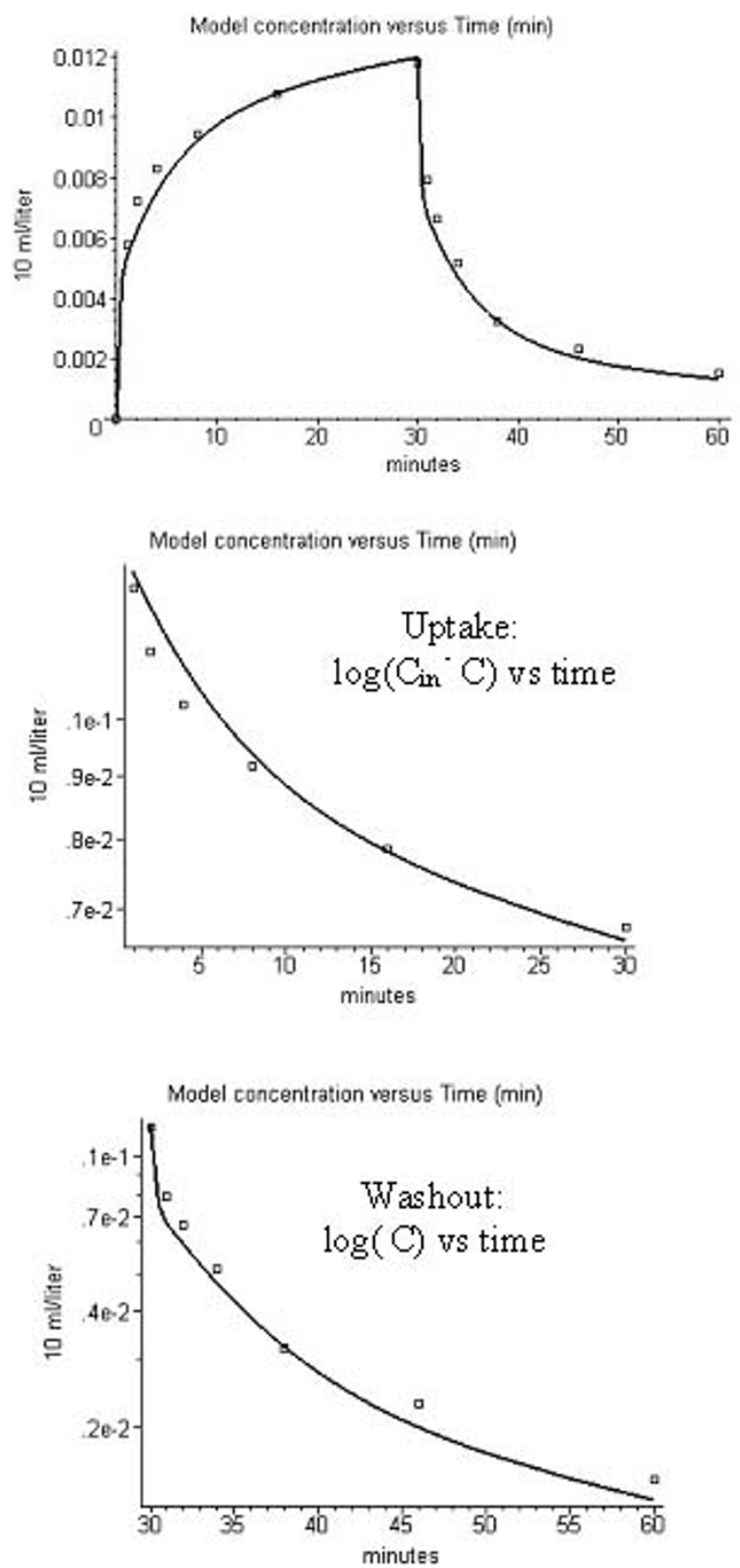

\section{Figure I}

Comparison of PKQuest model alveolar gas concentration (line) and experimental data (squares) for the end tidal concentration (volume \%) during uptake and washout of enflurane. The figures in the left hand column are for the data of Carpenter et al. [28] (inspired concentration $=0.518 \%$ ) and those in the right hand column are for data of Munson et al. [4] (inspired concentration $=0.0186 \%$ ). The figures in the second row are for the uptake in the form of a semi log plot of the difference between the inhaled concentration (which would correspond to the long time equilibrium concentration) and the end expired concentration as a function of time. The figures in the third row are a semi log plot of the end expired concentration as a function of time. The data are the mean values for 9 (Carpenter et al) and 6 (Munson et al.) subjects. 
assumed that the metabolism of $\mathrm{N}_{2} \mathrm{O}$ and enflurane is negligible $[24,27,28]$, and that the loss through the skin can be neglected [29].

The free water concentration $\left(\mathrm{C}_{\text {free }}\right)$ plays a central role in the PKQuest calculations (see [1] for details). For the blood or any organ, the free concentration can be related to the total (measured) concentration (Ctot) by the relation $\mathrm{C}_{\text {tot }}=\mathrm{C}_{\text {free }} \mathrm{wfract} / \mathrm{fw}$ where wfract is the water fraction in the organ and $\mathrm{fw}$ is the fraction of the solute that is free in the water phase. The parameter $\mathrm{fw}[\mathrm{i}]$, the fraction free in organ i (including vascular compartments), characterizes the fraction free (and bound) and the corresponding tissue/blood partition coefficients. In general, this parameter must be experimentally determined for each solute (and organ). However, for these volatile solutes it is assumed that the "bound" solute is equal to the solute dissolved in the blood or tissue lipid. For this case, the parameter fw [i] is completely determined by Kfwat (oil/water partition coefficient) and klip[i] (the fraction of lipid in each organ):

$\mathrm{fw}[\mathrm{i}]=\mathrm{wfract}[\mathrm{i}] /\left(\right.$ wfract $\left.[\mathrm{i}]+\mathrm{Kfwat}^{*} \operatorname{klip}[\mathrm{i}]\right)$

Although PKQuest uses only Kwair (water/air partition), Kfwat and klip[i] for the actual calculations, a variety of combinations of Kfwat, Kwair, Kbair (blood/air partition), Kbwat (blood/water partition), etc. can be entered. For example, for the anesthetics investigated here, the 3 parameters Kbair, Kwair and Kfwat are known experimentally and are entered. PKQuest then uses these 3 parameters to calculate the corresponding value for klip [blood] and replaces the default "standard human" value by this experimental value.

\section{Experimental pharmacokinetic data}

The experimental data was obtained from previous publications. The anesthetic data was based on the results in the papers by Carpenter et al. [5] and Munson et al. [4]. Both of these studies determined the simultaneous uptake and washout of nitrous oxide $\left(\mathrm{N}_{2} \mathrm{O}\right)$, enflurane, halothane, and methoxyflurane. Munson et al. used low, sub-anesthetic concentrations of all 4 gases with a total inhaled concentration of about $2 \%$ so that the second gas effect [30] was negligible. Carpenter et al. first induced anesthesia with high (65-70\%) concentrations of $\mathrm{N}_{2} \mathrm{O}$ and then, after the $\mathrm{N}_{2} \mathrm{O}$ had equilibrated, added the other 3 gases at concentrations about 20 times higher than that of Munson et al. (at a total inhaled concentration of less than $2 \%$ ) and then washed them out while maintaining constant $\mathrm{N}_{2} \mathrm{O}$ levels. Thus, the second gas effect can also be neglected for the data of Carpenter et al. for enflurane, halothane, and methoxyflurane (but not $\mathrm{N}_{2} \mathrm{O}$ ). The experimental data points were obtained by using UN-SCAN-IT (Silk Scientific Corporation) to read the data from the published figures (figs. 2 and 3, Munson et al.; figs. 1 and 2, Carpenter et al.).

The Munson et al data [4] represents the mean value for 6 healthy fasted unanesthetized males breathing for 30 minutes a gas containing $0.0069 \%$ methoxyflurane; $0.0136 \%$ halothane; $0.0186 \%$ enflurane; and $1.88 \%$ $\mathrm{N}_{2} \mathrm{O}$. The Carpenter et al. data [5] represents the mean values for 4 male and 5 female healthy subjects undergoing donor nephrectomy. The subjects were administered $65-70 \% \mathrm{~N}_{2} \mathrm{O}$ for 30 minutes and then a mixture of $0.348 \%$ isoflurane, $0.518 \%$ enflurane, 0.226 halothane and $0.0469 \%$ methoxyflurane was administered for 2 hours. After discontinuing these gases, anesthesia was maintained with fentanyl, thiopental and $\mathrm{N}_{2} \mathrm{O}$ for the duration of the operation. The Carpenter et al. washout data was collected at intervals during the first day, and once a day for the next 5 to 8 days. Since subjects became ambulatory upon recovering from surgery with the associated changes in PBPK parameters (eg. muscle blood flow, ventilation) only data out to 15 hours was used. In fitting this data it is assumed that using the mean values of the concentration versus time averaged over a population is equivalent to treating these values as representative of a single "average" person [31]. For this data with its relatively small standard error (typically \pm 2 to $3 \%$ of the inspired concentration), this should be a reasonably accurate assumption.

The toluene data was based on the published investigation of Pierce et al.[32]. Pierce et al. [32] exposed 26 male Caucasian subjects to $50 \mathrm{ppm}$ each of $1 \mathrm{H} 8$-toluene and 2H8-toluene for two hours at rest, and collected venous blood and alveolar breath samples for up to 120 hours. Their subject-specific PBPK explained 91\% of the observed data variability and found interindividual toxicokinetic differences. All the data for each individual in this series was generously provided by C.H. Pierce. Two different individuals in the Pierce et al. series were chosen to be modeled by PKQuest. The two subjects (subjects 5a and 15 in Table I of Pierce et al.) were chosen because they had large differences in percent fat content (38\% versus $22 \%$ ) and corresponding differences in toluene kinetics.

\section{Experimental partition coefficients}

The partition coefficients were based on previous published data. The values of Kwair for the anesthetics (enflurane 0.7; halothane $0.8 ; \mathrm{N}_{2} \mathrm{O} 0.47$; methoxyflurane 4.33 ) were from the review by Steward et al. [10]. The average values of blood/air partition coefficient for the Munson et al subjects ([4], Table II) were used for the anesthetics (enflurane 2.0; halothane 2.32; $\mathrm{N}_{2} \mathrm{O} 0.418$; methoxyflurane 13.9). The value of Kfwat was obtained from different sources (enflurane 130 [10], $\mathrm{N}_{2} \mathrm{O} 2.97$ [10], halothane 170 [33], methoxyflurane 208 [34]) Identical values were 


\section{Nitrous Oxide}

\section{Munson et. al.}
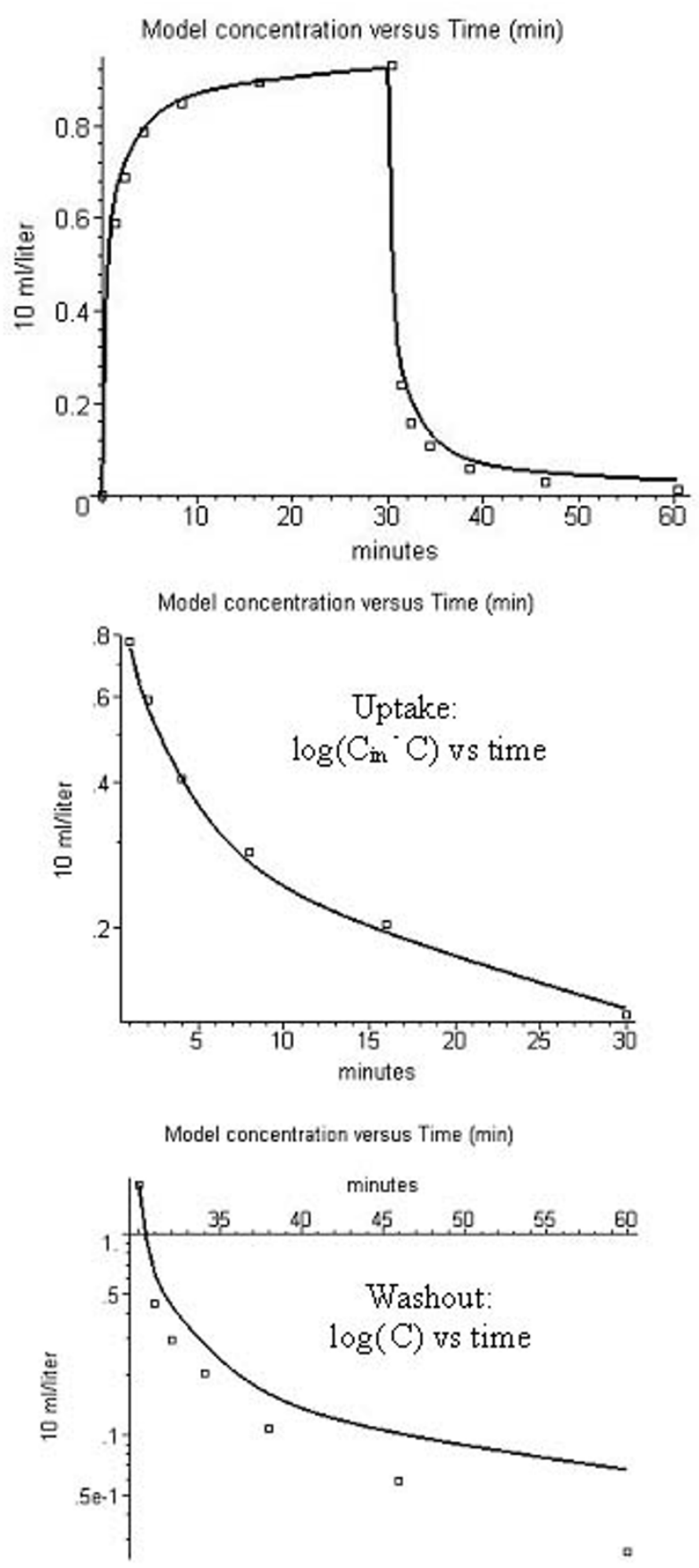

Figure 2

Comparison of model alveolar gas concentration (line) and experimental data for the end tidal concentration (volume \%) during uptake and washout of nitrous oxide (inhaled concentration $=1.88 \%)$. The figures in the 3 rows are similar to those in fig. I. used for modeling the Munson et al. and Carpenter et al. data.

For the toluene data, the value of the blood/air partition coefficient was measured for each of the two subjects that were modeled (Table I, [32]). The value of the lipid/air partition coefficient was based on the average value reported by Pierce et al. [35].

\section{Standard Human parameters}

The default standard values are stored as a Maple procedure in PKQuest. The values used for organ flows, volumes, etc. are identical to those used in all the other applications of PKQuest [1-3]. A list of some of the parameters is included in additional file 1. For a complete listing, see the routine on the web site [www.pkquest.com].

The critical new parameter set required for this application is the value of klip [i], the fraction of lipid in each organ i. This parameter (along with Kfwat) determines the tissue/water partition. This parameter set was determined by finding values of klip that would reproduce the tissue/ air partition coefficients reported by Zhou et [33] for a number of anesthetic solutes for human heart, brain, liver, muscle and fat and assuming that the other organs (skin, intestine, kidney) had similar values. The values of klip chosen for each organ are: liver 0.028; intestines 0.02; kidney 0.028; and all other organs 0.017 . The only other parameter that was adjusted to fit the data for these solutes was the fat blood flow. The PKQuest global (simulated annealing) and local (Powell) optimization routines were used to select the fat blood flow that provided the best fit to the enflurane data. This value was then used for all the other solutes that were investigated.

\section{PKQuest Maple input procedure}

The pharmacokinetics for each of the solutes is completely characterized by the Maple input procedure for that solute. The complete procedures are available on the web ( [www.pkquest.com]). A slightly abbreviated listing of the procedures for each of the solutes used in this paper is included in additional file 1.

\section{Results \\ Enfluane}

As described previously [1], each compound modeled by PKQuest is completely characterized by a short Maple ( [www.maplesoft.com]) procedure that lists the PKQuest parameters that are unique for that solute. The Maple procedure for enflurane for the data of Carpenter et al. [5] is listed here:

enflurane: $=\operatorname{proc}()$ 


\section{Halothane}

Carpenter et. al.

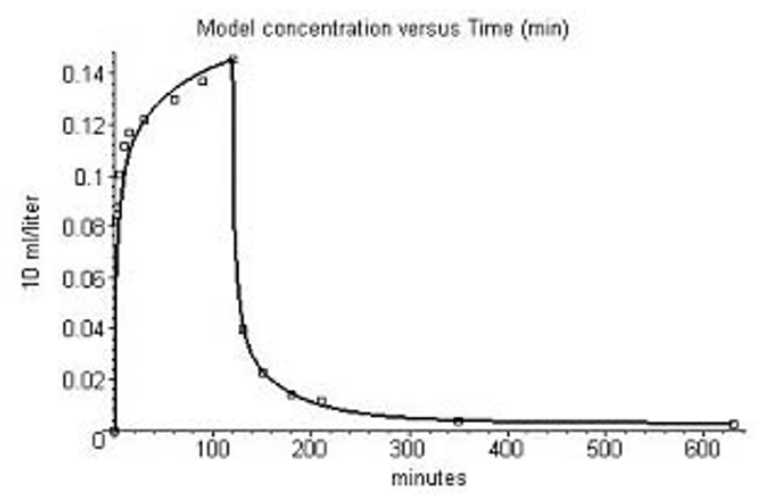

Model concentration versus Time (min)
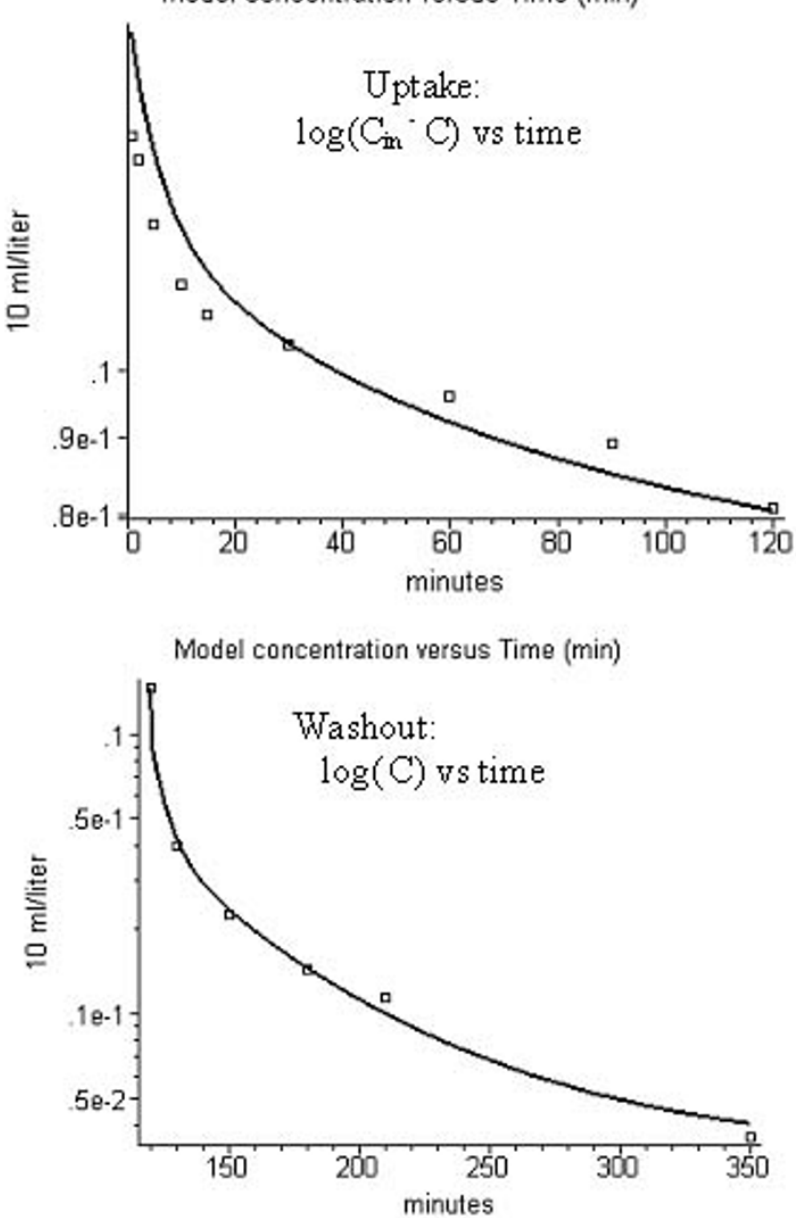

Munson et. al.
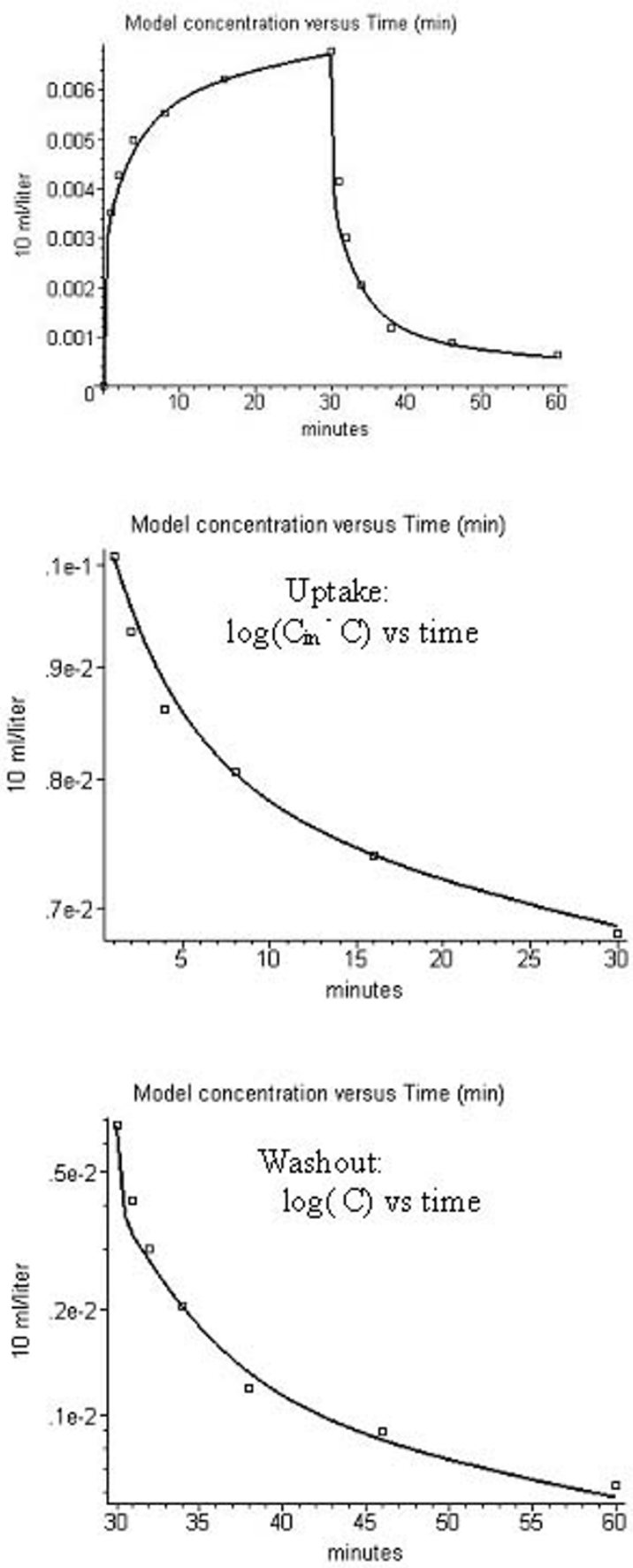

Figure 3

Comparison of model alveolar gas concentration (line) and experimental data for the end tidal concentration (volume \%) during uptake and washout of halothane. The left column is for the data of carpenter et al. [28] (inspired concentration $=0.226 \%$ ) and the right column is for the data of Munson et al. [4] (inspired concentration $=0.0135 \%$ ). The figures in the 3 rows are similar to those in fig. I. 
defaultpar():

Wtot:=70.0; \#Body weight

standardhuman(Wtot);

Fat:=0.25; \#average value for men and women

cunit:="10 ml";

Kbair:=2.0;\# blood/air partition coefficient - value for Munson fasted subjects.

Kwair:=0.75;\#water/air partition coefficient - standard reference value

Kfair:=98;\#fat/air partition coefficient - literature value

Kfwat:=Kfair/Kwair;

ninput:=1； finput[1]:=table $([$ organ=lung, type $=1$, rate $=0.518$, tbeg $=0$,

tend $=120$, csteady $=0$, padjust $=0]$ ); $\# 2$ hour constant lung input

The body weight was set arbitrarily to the standard value of $70 \mathrm{Kg}$ since the input dose should scale with body weight through the alveolar ventilation parameter. The fraction body fat (= Fat) was chosen based on the standard literature average value [36] for the 4 men and 5 women studied by Carpenter et al. Since PKQuest always uses units of liters, minutes and $\mathrm{Kg}$, the concentration of $\mathrm{ml}$ anesthetic/100 $\mathrm{ml}$ total volume (abbreviated as \%) used by Carpenter et al. corresponds to a "cunit" of $10 \mathrm{ml}$ per liter (this parameter is only used for display of output and does not directly enter the calculations). The value of Kbair is the average value reported by Munson et al. [4] for the fasting subjects. The value of Kwair is from the standard reference [10] and Kfair is based on measurements of solubility in olive oil [10] and in human fat tissue [33]. The input was a constant 120 minute inhaled concentration of $0.518 \%$. Note that all the parameters required to characterize enflurane are direct experimental measurements so that there are no adjustable parameters (see Discussion Section for further discussion of this point).

It should be emphasized that the above short procedure completely characterizes the enflurane PBPK. All the other parameters are determined by the default values set by the calls to defaultpar() and standardhuman(). (The user can override the default values and input an arbitrary value for any parameter.). The partition coefficients for the individual organs are determined by the default value for the fraction of lipid in each organ i (klip[i]).
The PKQuest output using this "enflurane" input procedure is shown in the left hand column of fig 1 along with the experimental data (squares) of Carpenter et al. [5]. The top figure shows the results during uptake and washout and the figures in the second and third rows show the semi log plots of the uptake and washout, respectively. All the figures shown in this paper are copied directly from the standard PKQuest output.

The corresponding plot for the enflurane data of Munson et al. [4] is shown in the right hand column of fig. 1. Exactly the same set of parameters were used except that: 1) the fraction of body fat was reduced to 0.16 , the standard literature average value [36] for the 12 young male subjects used in this study; and 2) the experimental inhaled enflurane concentration was $0.0186 \%$ for 30 minutes (versus $0.518 \%$ for 120 minutes for Carpenter et al). The fact that both sets of data can be fit using an identical parameter set, even though the concentrations differ by a factor of 28 , indicates that the enflurane pharmacokinetics must be linear over a large concentration range.

\section{Nitrous oxide}

Figure 2 compares the PKQuest output with the experimental data of Munson et al. [4] for $\mathrm{N}_{2} \mathrm{O}$. (The $\mathrm{N}_{2} \mathrm{O}$ data of Carpenter et al. could not be used because of the large second gas effect.). The partition coefficients used for this calculation are the standard $\mathrm{N}_{2} \mathrm{O}$ literature values: Kwair=0.47 [10]; Kfair=1.4 [10] and Kbair=0.418 (Munson et al. [4], fasting subjects). All the other parameters are identical to those used for the Munson et al. enflurane data.. (See additional file 1 for the complete $\mathrm{N}_{2} \mathrm{O}$ Maple procedure). The agreement between the PKQuest predictions and experiment is excellent for the $\mathrm{N}_{2} \mathrm{O}$ uptake. However, there is a significant deviation between the predictions and the data during the washout that is especially apparent in the semi log plot. There is no obvious explanation for this discrepancy and it may be artifactual (see Discussion Section).

\section{Halothane}

There is an additional complication when modeling the halothane data because a significant fraction of the halothane disappearance is the result of metabolism [24,27,28,37-41]. Loizou et al. [20] developed a detailed PBPK in the rat with the halothane metabolism described by a 4 parameter function that included both MichaelisMenten and inactivation components. Although there is qualitative evidence that halothane metabolism in humans is non-linear, saturating at higher concentrations [27], the quantitative aspects of halothane metabolism are poorly characterized in the human. Probably the most relevant data is provided by investigations in miniature swine. Sawyer et al. [38] reported that the percent liver clearance during the halothane washout in miniature 


\section{Methoxyflurane}

Carpenter et. al.

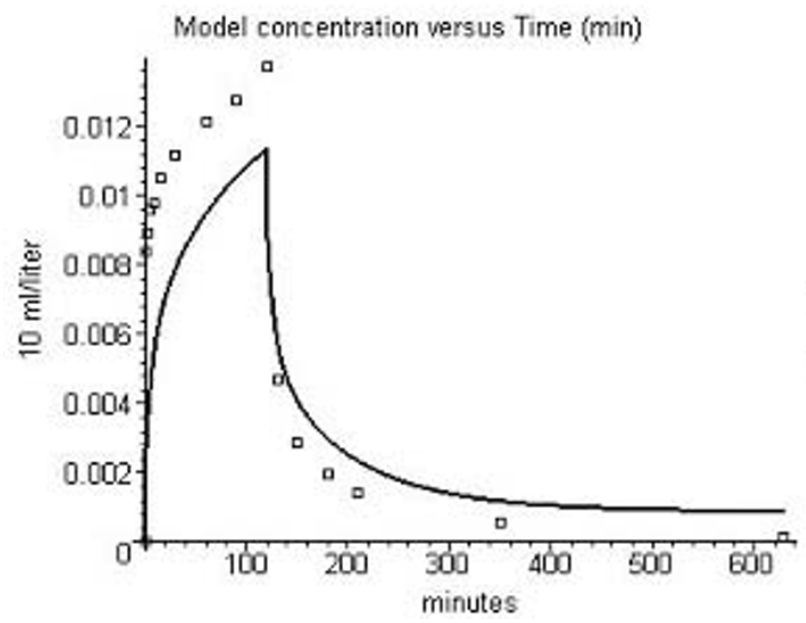

Munson et. al.

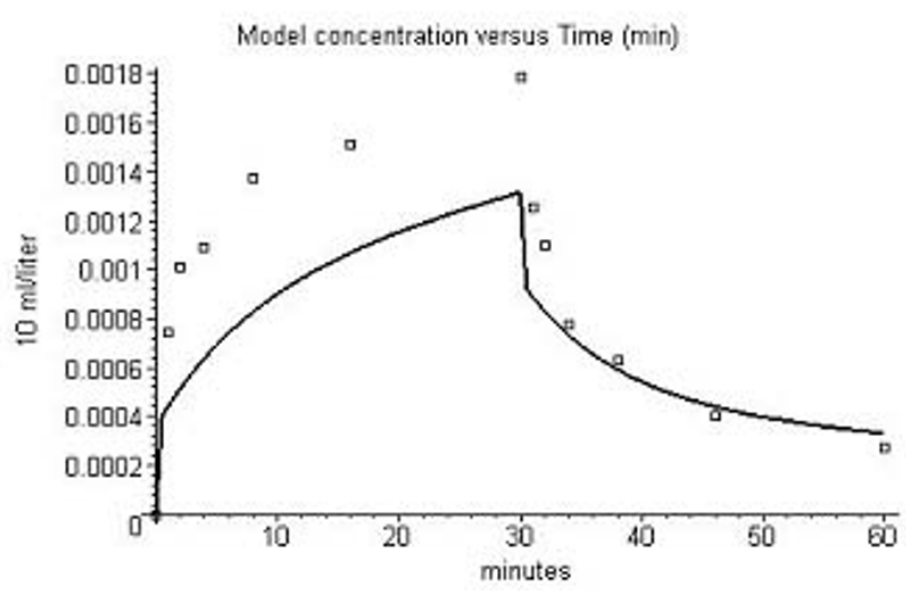

Figure 4

Comparison of model alveolar gas concentration (line) and experimental data for the end tidal concentration (volume \%) during uptake and washout of methoxyflurane. (No metabolism). Left column is data of carpenter et al. [28] (inspired concentration $=0.0469 \%$ ) and right column data of Munson et al. [4] (inspired concentration $=0.0069 \%$ ). The figures in the 3 rows are similar to those in fig. I.

swine was $77 \%$ at an alveolar concentrations of $0.0026 \%$ and fell to $5 \%$ at an alveolar concentration of $1 \%$. Halsey et al. [37] found that 35\% of the halothane entering the miniature swine liver was metabolized at a steady state alveolar concentration of $0.0065 \%$.

For this study it was assumed that the halothane metabolism could be described by a two parameter MichaelisMenten (Km and Vmax) liver component. The two parameters were adjusted to so that they a) provided a good fit to the experimental halothane data of both Carpenter et al. [5] (inhaled concentration of $0.226 \%$ ) and Munson et al. [4] (inhaled concentration of $0.0135 \%$ ) and b) were roughly consistent with the miniature swine data. The final values in partial pressure units were $\mathrm{Km}=0.01 \mathrm{ml} / 100$ $\mathrm{ml}$ and $\mathrm{Vmax}=0.6 \mathrm{ml} / \mathrm{min}$ for the standard $70 \mathrm{Kg}$ human. This corresponds to a water concentration for Km of 3.57 $\mu$ mole/liter and a Vm of $21.4 \mu$ mole/min. This $\mathrm{Km}$ is similar to the Km of $2.03 \mu$ mole/liter in the rat [20]. Given the limited human quantitative data that is available, these human metabolic parameters should be regarded only as a first approximation. Figure 3 shows that this set of metabolic constants provided a good fit to the 17 fold range of inhaled halothane concentrations used in the Carpenter et al. ( $0.226 \%$ concentration) and Munson et al. ( $0.0136 \%$ concentration) experiments. The partition coefficients used in these calculations were the standard lit- erature values: Kbair = 2.32 (Munsen et al. fasted subject); Kwair $=0.8$ [10] and Kfair = 137 [33]. (See additional file 1 for the complete halothane Maple procedure). For these parameters, the percent liver halothane clearance varied from $48 \%$ at an alveolar concentration of $0.0002 \%$; to $30 \%$ at a concentration of $0.07 \%$; to $7 \%$ at a concentration of $0.26 \%$ - similar to the swine data. Using the PKQuest PBPK results, $65 \%$ of the halothane should have been recovered during a 5 day washout period relative to the total uptake. This is somewhat greater than the $55 \%$ recovery directly estimated for this same data by measuring the mixed expired halothane concentration and ventilation rate once per day for 5 days [28]. The standard output of PKQuest provides all the above information (fractional liver clearance, recovery during washout, etc.).

\section{Methoxyflurane}

As shown by the results in figs. 1-3, PKQuest provides an accurate description of the human pharmacokinetics of the uptake and washout of enflurane and halothane and the uptake of $\mathrm{N}_{2} \mathrm{O}$. In contrast, the PKQuest predictions are clearly incorrect for methoxyflurane. Figures 4 show the PKQuest predictions for the alveolar concentration (solid line) compared with the experimental data of Carpenter et al. (fig 4, left column) and Monson et al. (fig. 4, right column). (See the additional file 1 for the complete methoxyflurane Maple procedure). The partition coeffi- 
cients used for these figures are the standard literature values: Kbair = 13.9 (Munson et al. [4] fasted subjects); Kfwat $=208$ [34]; Kwair $=4.0$ [42]. It can be seen that the PKQuest concentrations during uptake are about 30\% less than the experimental values. The actual error is even worse than this because these PKQuest predictions ignore metabolism, which can account for as much as $70 \%$ of the total removal $[24,27,28,37,43]$. Including metabolism would increase the difference between the PKQuest and experimental results during uptake. The explanation for this poor fit is provided in the Discussion section.

\section{Toluene}

Some of the most comprehensive and sophisticated human PBPKs have been developed to describe the pharmacokinetics of volatile toxic solvents such as toluene $[32,44,45]$, styrene [46,47], and methyl chloride [48]. The most involved models incorporate several different fat and muscle compartments with different flows and allow for changes with time in the blood flows as the subject's exercise level varies $[45,47,48]$. These studies have also introduced a Bayesian approach to determine the population distribution of the PBPK parameters $[45,47]$. PKQuest cannot complete with these PBPKs for this class of solutes. The only purpose of applying PKQuest to toluene is to show that the new approach developed here of using just klip and the oil/water partition coefficient to characterize the tissue partition is valid for a wider class of solutes than just the anesthetics gases (at least as a first approximation). PKQuest was applied to data for two individuals (subjects $5 \mathrm{a}$ and 15 ) that were chosen from the detailed investigations of Pierce et al.[32] because they had large differences in percent fat content (38\% versus $22 \%$ ) and corresponding differences in toluene kinetics.

The Maple input procedure for subject 15 is:

$$
\begin{aligned}
& \text { toluene_15:=proc }() \\
& \text { defaultpar( }) \text { : } \\
& \text { Wtot:=86.2; \#Body weight } \\
& \text { standardhuman(Wtot); } \\
& \text { Fat:=0.22; Fraction of body weight that is fat for subject } \\
& 15 \\
& \text { cunit:="micromole"; \# concentration in units of micro- } \\
& \text { mole/liter }
\end{aligned}
$$
conc ninput:=1； finput[1]:=table $([$ organ=lung, type $=1$, rate $=2.0$, tbeg $=0$,

tend $=120$, csteady $=0$, padjust=0]); \#2 hour constant input to the lung of $2 \mu \mathrm{M}$

Kfair:=962; fat/air partition coefficient

Kbair:=22.2; \# blood/air partition coefficient for subject 15

Kfbld:=Kfair/Kbair; \#Calculated fat/blood partition coefficient

alvent:=6.07; \# alveolar ventilation for subject 15

Tclr [liver]:=25.0;\#Liver clearance optimized to provides best fit to data

The total body weight (Wtot), body fat fraction (Fat), blood/air partition coefficient (Kbair) and alveolar ventilation (alvent) were measured for each individual subject (see Table I, Pierce et al. [32]) and these values were used as input. The value of the lipid/air partition coefficient (Kfair) was set equal to the average value determined by Pierce et al. [35]. Since Kwair is not input, PKQuest estimates Kwair using Kbair and Kfbld and the default fat content of blood (klip [vein]). The input function was a 2 hour inhalation of toluene at a constant gas concentration of $2 \mu \mathrm{M}$. The only adjustable parameters are the metabolic kinetic constants. The rat liver has a number of enzymes involved in toluene metabolism [49]. Since the Km for all of these enzymes is in the $\mathrm{mM}$ range, while the blood toluene concentrations for this data are in the $\mu \mathrm{M}$ range, it was assumed that the metabolism is linear which, in PKQuest, is indicated by using Tclr (in place of $\mathrm{Vm}$ and $\mathrm{Km}$ ). The value of Tclr was obtained by using the Powell minimization routine that is built into PKQuest to optimize the fit to the blood data. Pierce et al. [32] divided the metabolism between the liver and lung. However, since there is little direct information about human lung metabolism of toluene, it was assumed here that only the liver was involved in the metabolism.

Subject 5a was modeled using the same procedure using the body weight $(121 \mathrm{Kg})$, fat fraction (0.38) alveolar ventilation, and Kbair measured for this subject. (See the additional file 1 for the complete subject 5a Maple procedure). The value of Tclr for subject $5 \mathrm{a}$ was set equal to the Tclr of subject 15 scaled by body weight. All the other parameters were identical to those for subject 15 .

Figure 5 shows the agreement between the PKQuest predictions for the arterial (black) and venous (red) blood concentration and the experimental data for subject $5 \mathrm{a}$ 


\section{Toluene}
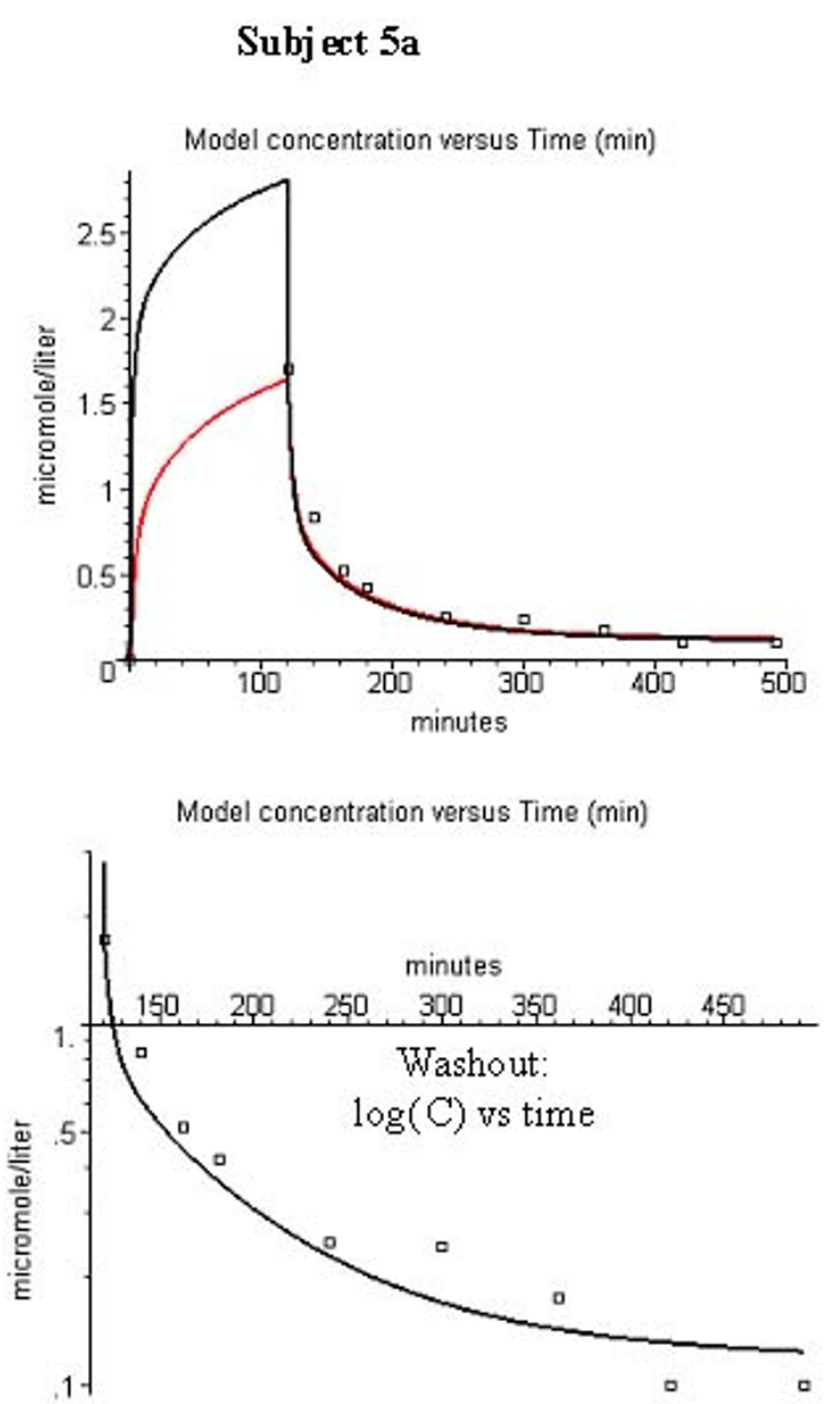

\section{Subject 15}
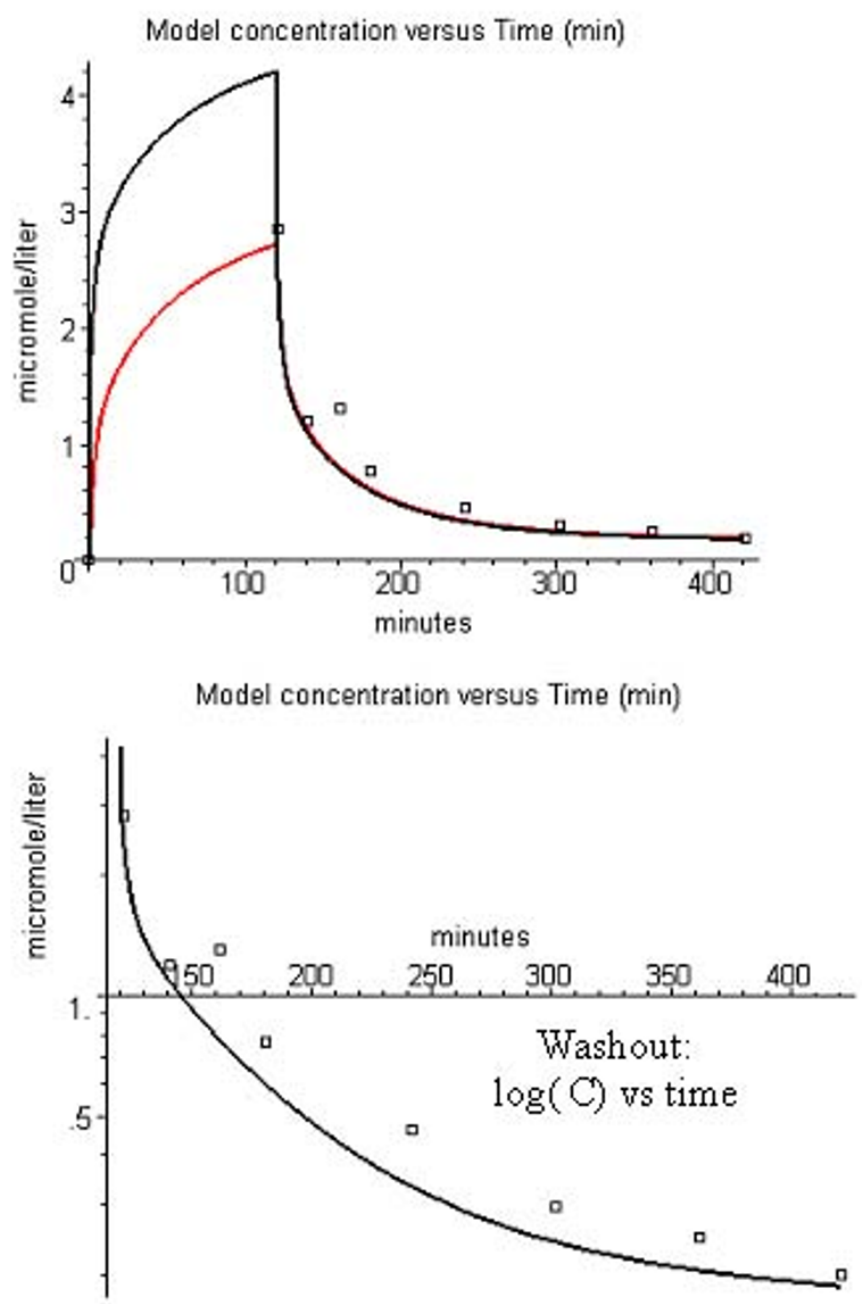

\section{Figure 5}

Comparison of model arterial (black) and venous (red) whole blood concentration ( $\mu \mathrm{M})$ and experimental arterialized blood data during washout of toluene. Left column is for subject 5 a, right column is for subject I5. The figures in the 3 rows are similar to those in fig. I.

(left hand column) and 15 (right hand column) during the time course of toluene washout. (PKQuest allows an arbitrary number of different organ concentrations to be simultaneously displayed). Pierce et al. sampled "arterialized" venous blood. Since the PKQuest venous and arterial concentrations are identical at the time points of the experimental data (fig. 5), the distinction between artery and vein is not significant. Figures 6 show the corresponding fits for the alveolar gas concentration. It can be seen that the agreement is quite good and the differences in the pharmacokinetics for the two subjects can be explained by differences in the fat fraction. It should be emphasized that there is only one adjustable parameter for these 2 subjects - the Tclr of subject 15 .

\section{Perfusion-Ventilation Mismatch}

A unique feature of PKQuest is that it provides a direct simulation of the mismatch between perfusion and ventilation. A detailed description of the equations and procedures used for this simulation is provided in the original paper [1]. Briefly, the lung is divided into Nlung equal volume compartments, with the blood flow (Q) and ven- 
tilation (V) to each compartment determined by a bivariate, uncorrelated, log-normal function [50];

$$
F(V, Q)=\left[\frac { 1 } { \sqrt { 2 \pi } \sigma _ { V } } \operatorname { e x p } ( - \frac { ( \operatorname { l n } V - \mu _ { V } ) ^ { 2 } } { 2 \sigma _ { V } ^ { 2 } } ] \left[\frac{1}{\sqrt{2 \pi} \sigma_{Q}} \exp \left(-\frac{\left(\ln Q-\mu_{Q}\right)^{2}}{2 \sigma_{Q}^{2}}\right]\right.\right.
$$

The value of Nlung is determined by the user input parameter N1dim (Nlung $\left.=(2 * \mathrm{~N} 1 \mathrm{dim})^{2}\right)$. The two parameters $\sigma_{\mathrm{Q}}$ and $\sigma_{\mathrm{V}}$ (the "log standard deviation") characterize the distribution of the blood perfusion $\left(\sigma_{\mathrm{Q}}\right)$ and the ventilation $\left(\sigma_{V}\right)$ to the different compartments of the lung. The default values of $\sigma_{\mathrm{Q}}$ and $\sigma_{\mathrm{V}}$ of 0.4 were determined by applying the analysis of Wilson and Beck [50] to the ventilation-perfusion ratio distribution for normal young men [51]. The rates of perfusion and ventilation to each lung compartment are assumed to be uncorrelated (see [1] for details). This assumption is consistent with recent direct measurements of regional perfusion and ventilation $[52,53]$. Results will be shown here for the case where the lung is divided into 16 equal volume compartments $(\mathrm{N} 1 \mathrm{dim}=2$, Nlung $=16)$. This provides a good test of the importance of perfusion-ventilation mismatch. (Increasing N1dim to 3, corresponding to 36 lung compartments, changes the results by less than $2 \%$ ). Using the default values of $\sigma_{\mathrm{Q}}$ and $\sigma_{\mathrm{V}}$ the fraction of total flow and total ventilation assigned to each of the 16 compartments is (flow fraction, ventilation fraction): $(.0432, .0423) ;(.0423$, $.0549) ;(.0423, .0659) ;(.0423 ; .0869) ;(.0549, .0423)$; $(.0549, .0549) ;(.0549, .0659) ;(.0549, .0869) ;(.0659$, $.0423)$; (.0659, .0549); (.0659, .0659); (.0659, .0869); $(.0869, .0423) ;(.0869, .0549) ;(.0869, .0659) ;(.0859$, $.0869)$.

Figure 7 shows the influence of perfusion-ventilation mismatch on the PKQuest results for the enflurane data of Munson et al. [4]. The predicted alveolar concentration is shown for a) the 1 compartment homogenous lung model (black); and the 16 compartment model with b) the default (normal) values for sig_v and sig_f $($ red); $c$ ) twice the normal values of sig_v and sig_f (green); and d) three times the normal values of sig_v and sig_f (blue). It can be seen that the 16 compartment model with normal sig_v and sig_f (red) is almost indistinguishable from the homogeneous 1 compartment model (black). Thus, normal values of perfusion-ventilation mismatch have no significant effect on the uptake and washout of enflurane. It is not until the normal values of sig_v and sig_f are increased by a factor of about 3 that differences become significant.

Although the effect of the perfusion-ventilation mismatch is small, it can be important for some experimental measurements. Figure 8 shows the alveolar (black), arterial (red) and venous (green) $\mathrm{N}_{2} \mathrm{O}$ concentration using the 16 compartment model and the default (normal) of values of sig_v and sig_f for the conditions of Munson et al. [4] with all concentrations expressed in terms of the partial pressure gas concentration. It can be seen that the perfusion-ventilation mismatch produces a small difference in the alveolar and arterial concentrations during uptake (for the 1 compartment lung model, alveolar and arterial concentrations would be identical). This result is in quantitative agreement with the experimental measurements of Eger et al [54] in conscious subjects: At 1.5 minutes, PKQuest $\mathrm{P}_{\text {art }} / \mathrm{P}_{\text {alv }}=0.92$; experimental $\mathrm{P}_{\text {art }} / \mathrm{P}_{\text {endtidal }}=$ 0.92; At 8 minutes: PKQuest $=0.98 \mathrm{l}$ experimental $=0.98$.

\section{Discussion and conclusions}

Enflurane, nitrous oxide, halothane and toluene

The simple PKQuest approach of using a single set of "standard human" values for the lipid fraction of each organ (klip) to predict tissue/blood partition provides an accurate prediction of the pharmacokinetics of these 4 volatile solute. The word "prediction" (and not "description") is purposely used here because most of the parameters are based on the default, previously determined set of PBPK data and there is a minimum of adjustable parameters. For example, in the PKQuest input for the enflurane pharmacokinetics (fig. 1) there are no adjustable parameters. Every constant in the procedure enflurane() listed above is pre-determined from previous measurements. In this sense, the time dependence of the alveolar enflurane concentration during washin and washout shown in fig. 1 is a true prediction, based on previous measurements.

This example for enflurane is slightly misleading because the default blood flow in "standard human" was adjusted to give the best fit to the enflurane data. The fat blood flow parameter plays an important role in determining the accuracy of the fit to the experimental data. Figure 9 compares the PKQuest output for enflurane using the default fat blood flow (0.056 liters $/ \mathrm{min} / \mathrm{Kg}$; black) and twice the default value (red). The generality of this fat blood flow value is evidenced by the good fit that was obtained when it was used in the modeling of the Munson et al. and Carpenter et al. data for halothane (fig. 3) and the Pierce et al. data for toluene (figs. 5 and 6), solutes for which the fat blood flow has a larger influence because of the larger value of the oil/water partition coefficient.

This use of the enflurane data to determine the fat blood flow illustrates one of the main advantages of having a PBPK program such as PKQuest that is general enough that it can be applied to a large variety of solutes. Since different solutes have different sensitivities to the different PBPK parameters, using a variety of solutes to optimize the parameters increases the validity of the PBPK. Other examples of PKQuest standard human parameters that were optimized this way are the muscle blood flow (optimized using human $\mathrm{D}_{2} \mathrm{O}$ pharmacokinetics [2]) and the 


\section{Toluene}
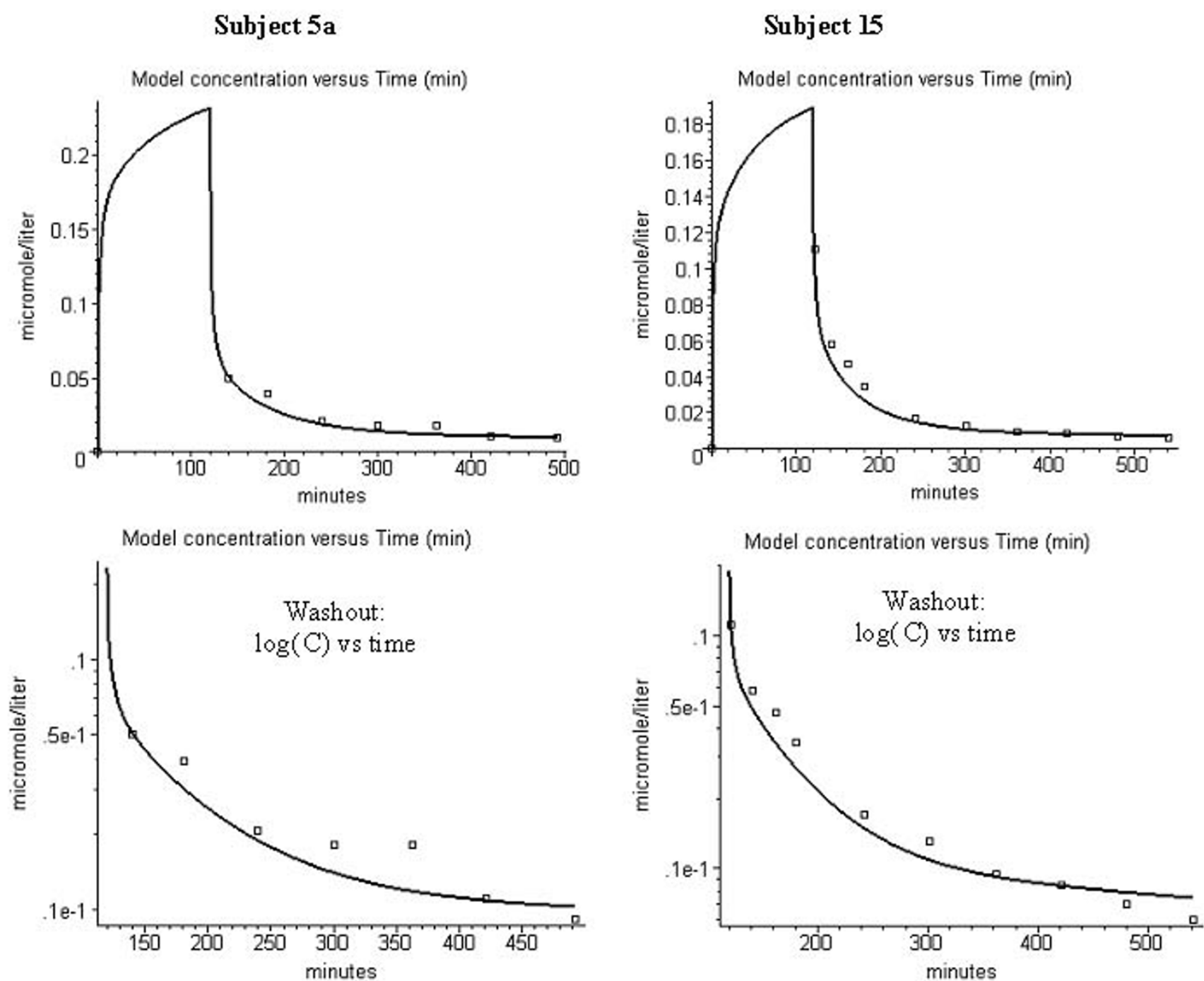

Figure 6

Comparison of model alveolar gas concentration (line) and experimental data for the end tidal concentration ( $\mu \mathrm{M}$ ) during washout of toluene. Left column is for subject $5 \mathrm{a}$, right column is for subject 15 . The figures in the 3 rows are similar to those in fig. 1 .

extracellular space (optimized using human inulin pharmacokinetics [3]).

The single most important difference between PKQuest and other PBPKs that have been applied to these solutes is the way the tissue/blood partition coefficient is handled. The conventional approach is to directly measure this partition coefficient for each solute in various classes of tissue in animals, and then use these values in the human model. In contrast, in PKQuest this partition coefficient is determined just from the value of the oil/water partition coefficient (along with the default value of the organ and blood lipid content). Since this partition coefficient is a simple physical chemical value and is usually available in the literature, this means that one can apply PKQuest to solutes even when no animal tissue partition data is available. The ability of this approach to describe the pharmacokinetics of solutes with an oil/water partition varying from $3\left(\mathrm{~N}_{2} \mathrm{O}\right)$ to 120 (toluene) demonstrates the large range of its validity.

The pharmacokinetic approach that seems to be currently favored for anesthetics is to use a general multi-compartment fit rather than a PBPK $[41,55]$. In this approach, the 


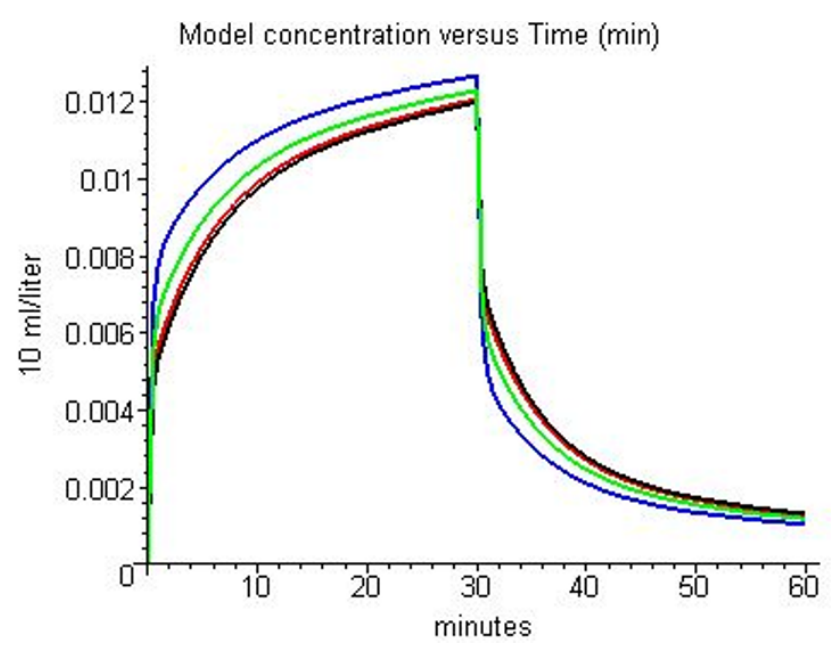

Figure 7

Effect of perfusion-ventilation mismatch on the model alveolar enflurane concentration: black: I compartment homogeneous model; red: 16 compartment model with default (normal) values of log standard deviation of flow and ventilation; green: 2 times normal values of log standard deviation; blue: 3 times normal values of log standard deviation.

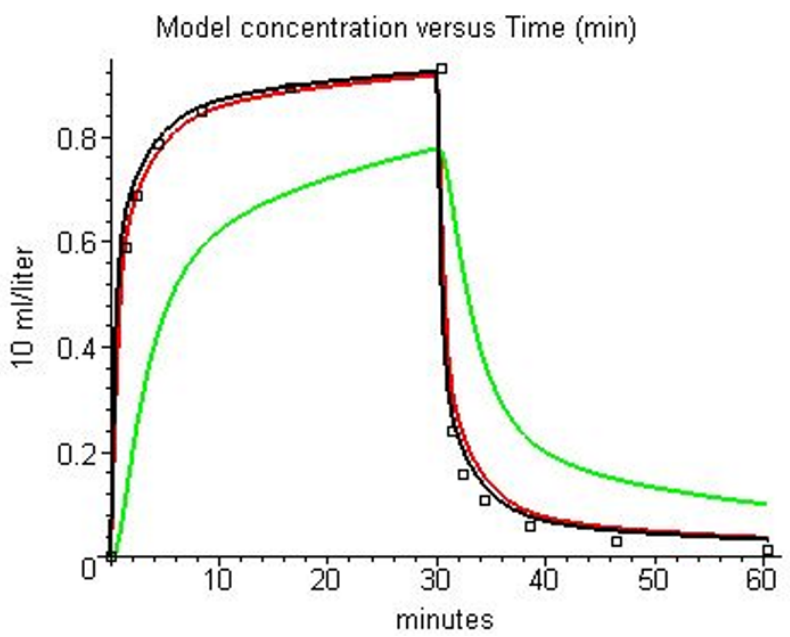

Figure 8

Effect of perfusion-ventilation mismatch on the model alveolar (black), arterial (red) and venous (green) partial pressure for nitrous oxide uptake and washout. Sixteen compartment lung model with default log standard deviations of perfusion and ventilation.

data is first fit with a multi-exponential function that is then interpreted in terms of exchanges between a central compartment (the vascular system) and an adjustable number of peripheral compartments (a "mammillary" system). Although this approach may be mathematically similar to a PBPK, it is completely different philosophical- ly. The advantage of the multi-compartment approach is that it is completely general and puts no restrictions or previous assumptions on the pharmacokinetic model. This advantage is also its main disadvantage. For example in a multi-compartment analysis of anesthetics by Yasuda et al. [41] there are 10 different rate constants that are optimized for each different anesthetic and these constants are then interpreted in terms of compartments and flows. In contrast, the major design feature of PKQuest is to have as many parameters as possible set by default based on previously determined measurements, with the amount of user input reduced to its absolute minimum. For the case of the typical volatile solute described here, the user only needs to input the water/air and oil/water partition coefficients and the metabolic parameters. All the other parameters required for the PBPK (organ volumes, blood flows, alveolar ventilation, organ/blood partition and volume, etc.) are determined simply by a call to "standardhuman". By using all the previous information that is available to restrict the model and minimize the number of adjustable parameters, PKQuest greatly increases the predictive power of the analysis.

The one exception to the generally good agreement between the PKQuest predictions and the experimental data for these solutes is for the washout of $\mathrm{N}_{2} \mathrm{O}$ (fig. 2). Although the differences between the PKQuest and experimental data are small in absolute value, they represent large relative values. For example, for the last data point (60 minutes), the PKQuest prediction for the end expired gas concentration is $0.067 \%$ while the experimental value is $0.026 \%$ (for an inhaled concentration of $1.88 \%$ ). (This difference is larger than the standard error of the last data point.) This difference may be artifactual. For example, the experimental $\mathrm{N}_{2} \mathrm{O}$ data (fig. 2) has a marked difference in the degree of equilibrium reached during uptake $(93 \%)$ versus washout $(98.7 \%)$. This result is not expected theoretically and is not consistent with the detailed experimental results of Salamitre et al. [56] who found approximately equal equilibration times during uptake and washout of sub anesthetic doses of $\mathrm{N}_{2} \mathrm{O}$. Another indication of the problem presented by this discrepancy is that it was not possible to significantly improve the fit by adjusting any or all of the PKQuest parameters. Any parameter change that improved the fit for the washout, significantly worsened the fit for the uptake and the addition of a perfusion-ventilation mismatch did not improve the fit. One possible explanation is a small error in the quantitative measurements (made in 1977) of Munsen et al [4] at low $\mathrm{N}_{2} \mathrm{O}$ concentrations. Other possibilities are a difference in some physiological parameters (e.g. ventilation) during uptake and washout or an error in reading the data off the published linear plot. 


\section{Methoxyflurane}

Methoxyflurane is a notable exception to the generally good agreement between the PKQuest PBPK and the experimental data. For methoxyflurane, the experimental end tidal partial pressure (squares, fig. 4) is about $30 \%$ greater than the PKQuest prediction during uptake (line, fig. 4). It is assumed in the PBPK model that the arterial blood and alveolar gas partial pressures are equal and correspond to the experimentally measured end tidal gas partial pressure. Thus the error in fig. 4 is equivalent to the statement that "the arterial partial pressure is significantly less than the end tidal partial pressure". This discrepancy for methoxyflurane had been noted previously in the older literature. Holaday et al. [57] reported that during methoxyflurane uptake, the arterial partial pressure was only about $50 \%$ of the end expired value. Similarly, Stoelting [58] observed that at the end of the methoxyflurane uptake, the arterial partial pressure was $60 \%$ of the end expired, while during washout, the two values were nearly identical. Despite these clear indications that there was something anomalous about methoxyflurane, this problem seems to have been generally ignored in the recent literature.

This inequality is almost certainly caused by the classic "washin-washout" artifact that has been described for gases with large blood/air partition (Kbair) coefficients [47,59-65]. This artifact is created when, during inspiration, the high concentration gas dissolves in the tissues of the bronchial tree, and then, during expiration, moves back into the air, raising the end tidal concentration above the alveolar values. For extremely soluble solutes such as ethanol (Kbair = 1756), the expired gas concentration is dominated by exchange with the conducting airway and is almost independent of the alveolar concentration $[63,65]$. For gases of intermediate solubility, such as styrene (Kbair $=48$ ) or toluene (Kbair $=18)$ the effect is less dramatic and has often been overlooked. This analysis provides a good example of the advantage of a PBPK such as PKQuest over the more general compartmental (mamillary) model. It is obvious from the PKQuest analysis (see fig. 4) that some model assumption must be wrong. In contrast, in a detailed compartmental (mammillary) model analysis of the simultaneous uptake and washout of methoxyflurane and other gases it was recognized that methoxyflurane was different, but the "reason for this discrepancy is not clear" [66].

The strongest evidence supporting this explanation for the discrepancy in the methoxyflurane data is provided by a comparison with toluene. Since the blood/air partition coefficients are similar for toluene $($ Kbair $=18)$ and methoxyflurane $($ Kbair $=13.9)$, this artifact should be of similar magnitude for these two solutes. During the uptake of toluene in resting subjects, the end tidal partial pressure is

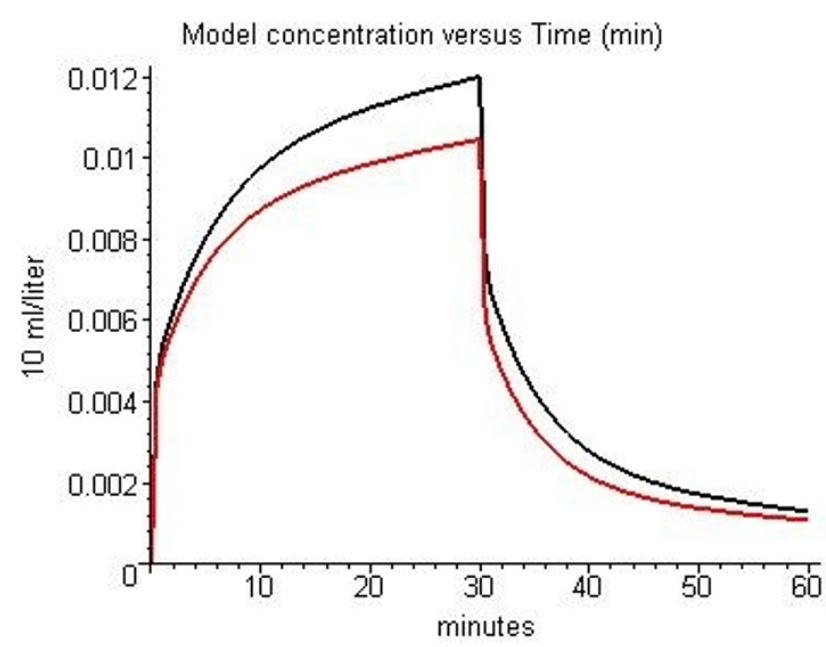

Figure 9

Effect of fat blood flow on model alveolar enflurane concentration (volume \%). Black: default fat blood flow (0.056 liters/ $\min / \mathrm{Kg}$ ); Red: 2 times default value.

only about $1 / 2$ the arterial value [67], similar to what is observed for methoxyflurane ([57,68], and see fig. 4). However, when these same subjects begin to exercise, increasing the ventilatory rate by a factor of 2.5 , the arterial and end tidal gas concentrations become approximately equal [67]. Presumably, at the higher rates of ventilation, there is relatively less time for exchange with the airways, and the artifact decreases. This suggests that solutes such as methoxyflurane or toluene are right on the boundary of where this artifact becomes important. The artifact becomes negligible for halothane with a Kbair of 2.2 as indicated by the nearly identical end tidal and arterial partial pressures [58], and the good agreement between the PKQuest results and the experimental data (see fig. 3).

For solutes such as toluene [45,67], styrene [47] and methoxyflurane [58] there is, at first glance, a peculiar asymmetry in the data that has caused some confusion: during uptake there is a large difference in the end tidal and arterial partial pressures, while, during washout, there is only a small or negligible difference. However, this asymmetry disappears if the data is reexamined as follows: For the resting toluene data of Carlsson et al. [67] during uptake the inspired concentration is $300 \mathrm{mg} / \mathrm{m}^{3}$, the end tidal concentration is $72 \mathrm{mg} / \mathrm{m}^{3}$, and the arterial concentration is $585 \mathrm{mg} / \mathrm{m}^{3}$. Assuming a Kbair of 18, this arterial concentration corresponds to a gas concentration of 32 $\mathrm{mg} / \mathrm{m}^{3}$, an end tidal - arterial difference of $55 \%$. If the artifact were not present and the end tidal equaled the arterial, then the end tidal concentration should have been 32 $\mathrm{mg} / \mathrm{m}^{3}$. Thus, the net rate of gas uptake (inspired - end tidal) is decreased about $13 \%(=(72-32) / 300)$ by the artifact. If a symmetrical error was present during washout, 
the washout rate should also be decreased by $13 \%$ by the artifact. Since, during washout, the inspired concentration is zero, this means that the washout end tidal concentration should be $13 \%$ less than the arterial partial pressure. Thus, if the artifact was symmetrical, the difference between the end tidal and arterial partial pressure during washout should be only about $1 / 5$ of the difference during uptake (13\% versus $55 \%$ difference). Errors of this magnitude $(13 \%)$ can be swamped by the normal variations in Kbair that result from variations in the blood fat content.

The observant reader should, at this point, be asking why toluene can be modeled by PKQuest (figs. 5 and 6) if it has a similar Kbair and, therefore, similar washin-washout artifact as methoxyflurane. There are 2 reasons: 1 ) Only the washout data was modeled so that one would expect only a small (13\%) error; and 2) This small error in the washout data was not present because the value of Kbair that was used for this modeling (Table I, Pierce et al [32]) was determined from the experimental ratios of the blood/end tidal air for each subject, and, thus, automatically compensated for this artifact. The fact that the average value of this "in vivo" Kbair was about $10 \%$ larger than the "in vitro" value [32] is consistent with an end tidal partial pressure that is $10 \%$ less than the arterial partial pressure.

\section{Competing interests}

None declared.

\section{Additional material}

\section{Additional files}

Supplementary information: I) Selected "standard human" values; and II) PKQuest Maple procedures describing each solute.

Click here for file

[http://www.biomedcentral.com/content/supplementary/14712253-2-5-s1.doc]

\section{Acknowledgements}

I wish to thank Crispin H. Pierce, Russell L. Dills, Michael S. Morgan, and David A. Kalman for providing detailed experimental data for all the subjects in their study [32]. I also want to thank the two reviewers of this manuscript, Laurence Mather and Fredrik Jonsson, for their many valuable comments and suggestions.

\section{References}

I. Levitt DG: PKQUEST: A general physiologically based pharmacokinetic model. Introduction and application to propranolol. BMC Clinical Pharmacology 2002, 2:5

2. Levitt DG: PKQUEST: Measurement of Intestinal Absorption and First Pass Metabolism - Application to Human Ethanol Pharmacokinetics. BMC Clinical Pharmacology 2002, 2:4

3. Levitt DG: PKQUEST: Capillary Permeability Limitation and Plasma Protein Binding - Application to Human Inulin, Di- cloxacillin and Ceftriaxone Pharmacokinetics. Submitted: BMC Clinical Pharmacology 2002

4. Munson ES, Eger El 2nd, Tham MK, Embro WJ: Increase in anesthetic uptake, excretion, and blood solubility in man after eating. Anesth Analg 1978, 57:224-31

5. Carpenter RL, Eger El 2nd, Johnson BH, Unadkat JD, Sheiner LB: Pharmacokinetics of inhaled anesthetics in humans: measurements during and after the simultaneous administration of enflurane, halothane, isoflurane, methoxyflurane, and nitrous oxide. Anesth Analg 1986, 65:575-82

6. Bergman NA: The legacy of John Snow. An appreciation of his life and scientific contribution on the 100th anniversary of his death. Anethesiology 1958, 19:595-606

7. Mapleson WW: Circulation-time models of the uptake of inhaled anaesthetics and data for quantifying them. $\mathrm{Br} J$ Anaesth 1973, 45:319-34

8. Davis NR, Mapleson WW: A physiological model for the distribution of injected agents, with special reference to pethidine. BrJ Anaesth 1993, 70:248-58

9. Davis NR, Mapleson WW: Structure and quantification of a physiological model of the distribution of injected agents and inhaled anaesthetics. Br J Anaesth I 981, 53:399-405

10. Steward A, Allott PR, Cowles AL, Mapleson WW: Solubility coefficients for inhaled anaesthetics for water, oil and biological media. Br J Anaesth 1 973, 45:282-93

II. Steward A, Allott PR, Mapleson WW: The solubility of halothane in canine blood and tissues. Br J Anaesth 1975, 47:423-34

12. Saraiva RA, Willis BA, Steward A, Lunn JN, Mapleson WW: Halothane solubility in human blood. Br J Anaesth 1977, 49:1 I5-9

13. Zwart A, Smith NT, Beneken JE: Multiple model approach to uptake and distribution of halothane: the use of an analog computer. Comput Biomed Res 1972, 5:228-38

14. Smith NT, Zwart A, Beneken JE: Interaction between the circulatory effects and the uptake and disribution of halothane: use of a multiple model. Anesthesiology 1972, 37:47-58

15. Fukui Y, Smith NT: Interactions among ventilation, the circulation, and the uptake and distribution of halothane - use of a hybrid computer multiple model: I. The basic model. Anesthesiology 1981, 54:107-18

16. Fukui Y, Smith NT: Interactions among ventilation, the circulation, and the uptake and distribution of halothane - use of a hybrid computer multiple model: II. Spontaneous vs. controlled ventilation, and the effects of CO2. Anesthesiology 198I, 54:119-24

17. Mapleson WW, Smith WD, Siebold K, Hargreaves MD, Clarke GM: Nitrous oxide anaesthesia induced at atmospheric and hyperbaric pressures. II. Comparison of measured and theoretical pharmacokinetic data. $\mathrm{Br}$ J Anaesth 1974, 46: I3-28

18. Brandom BW, Brandom RB, Cook DR: Uptake and distribution of halothane in infants: in vivo measurements and computer simulations. Anesth Analg 1983, 62:404-10

19. Allott PR, Steward A, Mapleson WW: Pharmacokinetics of halothane in the dog. Comparison of theory and measurement in individuals. $\mathrm{Br} J$ Anaesth 1976, 48:279-95

20. Loizou GD, Tran CL, Anders MW: Physiologically based pharmacokinetic analysis of the concentration-dependent metabolism of halothane. Xenobiotica 1997, 27:87-99

21. Lifson N, Levitt DG, Griffen WO Jr, Ellis CJ: Intrahepatic distribution of hepatic blood flow: double-input studies. Am J Physiol 1970, 2 18: 1480-8

22. Griffen WO Jr, Levitt DG, Ellis C], Lifson N: Intrahepatic distribution of hepatic blood flow: single-input studies. Am J Physiol 1970, 2 1 8: 1474-9

23. Doolette DJ, Upton RN, Grant C: Diffusion-limited, but not perfusion-limited, compartmental models describe cerebral nitrous oxide kinetics at high and low cerebral blood flows. J Pharmacokinet Biopharm 1998, 26:649-72

24. Sakai T, Takaori M: Biodegradation of halothane, enflurane and methoxyflurane. Br ] Anaesth | 978, 50:785-9|

25. Garton KJ, Yuen P, Meinwald J, Thummel KE, Kharasch ED: Stereoselective metabolism of enflurane by human liver cytochrome P450 2EI. Drug Metab Dispos 1995, 23: | 426-30

26. Mather LE, Fryirs BL, Duke CC, Cousins MJ: Lack of whole-body pharmacokinetic differences of halothane enantiomers in the rat. Anesthesiology 2000, 92:190-6 
27. Cahalan MK, Johnson $\mathrm{BH}$, Edger El 2nd: Relationship of concentrations of halothane and enflurane to their metabolism and elimination in man. Anesthesiology 1981, 54:3-8

28. Carpenter RL, Eger El 2nd, Johnson BH, Unadkat JD, Sheiner LB: The extent of metabolism of inhaled anesthetics in humans. Anesthesiology 1986, 65:20I-5

29. Fassoulaki A, Lockhart SH, Freire BA, Yasuda N, Eger EI 2nd, Weiskopf RB, Johnson BH: Percutaneous loss of desflurane, isoflurane, and halothane in humans. Anesthesiology 1991, 74:479-83

30. Taheri S, Eger El 2nd: A demonstration of the concentration and second gas effects in humans anesthetized with nitrous oxide and desflurane. Anesth Analg 1999, 89:774-80

31. Sheiner LB, Ludden TM: Population pharmacokinetics/dynamics. Annu Rev Pharmacol Toxicol 1992, 32:185-209

32. Pierce $\mathrm{CH}$, Dills RL, Morgan MS, Nothstein GL, Shen DD, Kalman DA: Interindividual differences in $2 \mathrm{H8}$-toluene toxicokinetics assessed by semiempirical physiologically based model. Toxicol Appl Pharmacol 1996, I39:49-61

33. Zhou JX, Liu J: The effect of temperature on solubility of volatile anesthetics in human tissues. Anesth Analg 2001, 93:234-8

34. Lerman J, Schmitt-Bantel BI, Gregory GA, Willis MM, Eger El 2nd: Effect of age on the solubility of volatile anesthetics in human tissues. Anesthesiology 1986, 65:307-II

35. Pierce CH, Dills RL, Silvey GW, Kalman DA: Partition coefficients between human blood or adipose tissue and air for aromatic solvents. Scand I Work Environ Health 1996, 22: I I 2-8

36. Chumlea WC, Guo SS, Zeller CM, Reo NV, Baumgartner RN, Garry PJ, Wang J, Pierson RN Jr, Heymsfield SB, Siervogel RM: Total body water reference values and prediction equations for adults. Kidney Int 200I, 59:2250-8

37. Halsey MJ, Sawyer DC, Eger El 2nd, Bahlman SH, Impelman DM: Hepatic metabolism of halothane, methoxyflurane, cyclopropane, Ethrane, and Forane in miniature swine. Anesthesiology | 97|, 35:43-7

38. Sawyer DC, Eger El 2nd, Bahlman SH, Cullen BF, Impelman D: Concentration dependence of hepatic halothane metabolism. Anesthesiology 1971, 34:230-5

39. Gourlay GK, Adams JF, Cousins MJ, Sharp JH: Time-course of formation of volatile reductive metabolites of halothane in humans and an animal model. BrJ Anaesth 1980, 52:331-6

40. Selinsky BS, Thompson M, London RE: Measurements of in vivo hepatic halothane metabolism in rats using I9F NMR spectroscopy. Biochem Pharmacol 1987, 36:413-6

41. Yasuda N, Lockhart SH, Eger El 2nd, Weiskopf RB, Johnson BH, Freire BA, Fassoulaki A: Kinetics of desflurane, isoflurane, and halothane in humans. Anesthesiology 1991, 74:489-98

42. Lerman J, Willis MM, Gregory GA, Eger El 2nd: Osmolarity determines the solubility of anesthetics in aqueous solutions at $\mathbf{3 7}$ degrees C. Anesthesiology 1983, 59:554-8

43. Holaday DA, Rudofsky S, Treuhaft PS: The metabolic degradation of methoxyflurane in man. Anesthesiology 1970, 33:589-93

44. Tardif R, Charest-Tardif G, Brodeur J, Krishnan K: Physiologically based pharmacokinetic modeling of a ternary mixture of alkyl benzenes in rats and humans.

45. Jonsson F, Johanson G: Bayesian estimation of variability in adipose tissue blood flow in man by physiologically based pharmacokinetic modeling of inhalation exposure to toluene. Toxicology 2001, 157:177-93

46. Ramsey JC, Andersen ME: A physiologically based description of the inhalation pharmacokinetics of styrene in rats and humans. Toxicol Appl Pharmacol 1984, 73: I59-75

47. Jonsson F, Johanson G: Physiologically Based Modeling of the Inhalation Kinetics of Styrene in Humans Using a Bayesian Population Approach. Toxicol Appl Pharmacol 2002, I 79:35-49

48. Jonsson F, Bois FY, Johanson G: Assessing the reliability of PBPK models using data from methyl chloride-exposed, non-conjugating human subjects. Arch Toxicol 2001, 75:189-99

49. Wang RS, Nakajima T: Kinetic studies on toluene metabolism in ethanol- and phenobarbital-induced rat liver microsomes in vitro. Arch Toxicol 1991, 65:39-44

50. Wilson TA, Beck KC: Contributions of ventilation and perfusion inhomogeneities to the VA/Q distribution. J Appl Physiol 1992, 72:2298-304

5I. Wagner PD, Laravuso RB, Uhl RR, West JB: Continuous distributions of ventilation-perfusion ratios in normal subjects breathing air and 100 per cent 02. J Clin Invest 1974, 54:54-68
52. Gerbino AJ, McKinney S, Glenny RW: Correlation between ventilation and perfusion determines VA/Q heterogeneity in endotoxemia. J Appl Physiol 2000, 88:1933-42

53. Treppo S, Mijailovich SM, Venegas JG: Contributions of pulmonary perfusion and ventilation to heterogeneity in $\mathrm{V}(\mathrm{A}) / \mathrm{Q}$ measured by PET. J Appl Physiol 1997, 82: I I63-76

54. Eger El 2nd, Babad AA, Regan MJ, Larson CP Jr, Shargel R, Severinghaus JW: Delayed approach of arterial to alveolar nitrous oxide partial pressures in dog and in man. Anesthesiology 1966, 27:288-97

55. Charkes ND: Physiological significance of the rate constants in compartmental analysis. Nucl Med Commun 200I, 22:33I-9

56. Salanitre E, Rackow H, Greene LT, Klonymus D, Epstein RM: Uptake and excretion of subanesthetic concentrations of nitrous oxide in man. Anesthesiology 1962, 23:8|4-822

57. Holaday DA, Garfield J, Ginsberg D: Methoxyflurane gradients in man during anethesia. Anethesiology 1965, 26:25।-252

58. Stoelting RK: Halothane and methoxyflurane concentrations in end-tidal gas, arterial blood, and lumbar cerebrospinal fluid. Anesthesiology 1973, 38:384-8

59. Cander L, Forster RE: Determination of pulmonary parenchymal tissue volume and pulmonary capillary blood flow in man. J. Applied Physiology 1959, 14:54|-55I

60. Schrikker AC, de Vries WR, Zwart A, Luijendijk SC: Uptake of highly soluble gases in the epithelium of the conducting airways. Pflugers Arch 1985, 405:389-94

6I. Tsu ME, Babb AL, Sugiyama EM, Hlastala MP: Dynamics of soluble gas exchange in the airways: II. Effects of breathing conditions. Respir Physiol 1991, 83:261-76

62. Johanson $\mathrm{G}$ : Modelling of respiratory exchange of polar solvents. Ann Occup Hyg 1991, 35:323-39

63. George SC, Babb AL, Hlastala MP: Dynamics of soluble gas exchange in the airways. III. Single-exhalation breathing maneuver. J Appl Physiol 1993, 75:2439-49

64. Petreas MX, Woodlee J, Becker CE, Rappaport SM: Retention of styrene following controlled exposure to constant and fluctuating air concentrations. Int Arch Occup Environ Health 1995, 67:27-34

65. George SC, Hlastala MP, Souders JE, Babb AL: Gas exchange in the airways. J Aerosol Med 1996, 9:25-33

66. Strum DP, Eger El 2nd, Unadkat JD, Johnson BH, Carpenter RL: Age affects the pharmacokinetics of inhaled anesthetics in humans. Anesth Analg 1991, 73:310-8

67. Carlsson A: Exposure to toluene: uptake, distribution and elimination in man. Scand ] Work Environ Health 1982, 8:43-55

68. Stoeckel K, McNamara PJ, Brandt R, Plozza-Nottebrock H, Ziegler WH: Effects of concentration-dependent plasma protein binding on ceftriaxone kinetics. Clin Pharmacol Ther 1981, 29:6507

\section{Pre-publication history}

The pre-publication history for this paper can be accessed here:

http://www.biomedcentral.com/1471-2253/2/5/prepub

Publish with BioMed Central and every scientist can read your work free of charge

"BioMedcentral will be the most significant development for disseminating the results of biomedical research in our lifetime." Paul Nurse, Director-General, Imperial Cancer Research Fund

Publish with BMC and your research papers will be:

- available free of charge to the entire biomedical community

- peer reviewed and published immediately upon acceptance - cited in PubMed and archived on PubMed Central - yours - you keep the copyright 